\title{
Rainfall, evapotranspiration and rainfall deficit trend in Alor Setar, Malaysia
}

\author{
Aimi Athirah Ahmad ${ }^{\text {a, b }}$, Fadhilah Yusof ${ }^{\text {b, }}$, Muhamad Radzali Mispan ${ }^{\text {c }}$, Hasliana Kamaruddin ${ }^{\mathrm{c}}$ \\ a Economic and Social Science Research Centre, Malaysian Agriculture Research and Development Institute, 43400 Serdang Selangor, Malaysia \\ ${ }^{b}$ Department of Mathematical Sciences, Faculty of Science, Universiti Teknologi Malaysia, 81310 UTM Johor Bahru, Johor, Malaysia \\ ${ }^{c}$ Agrobiodiversity and Environment Research Centre, Malaysian Agriculture Research and Development Institute, 43400 Serdang Selangor, \\ Malaysia \\ * Corresponding author: fadhilahy@utm.my
}

\section{Article history}

Received 16 October 2017

Accepted 8 November 2017

\begin{abstract}
Rainfall and potential evapotranspiration are important variables in water balance study. Rainfall data were obtained from Malaysian Meteorological Department while estimates of potential evapotranspiration were calculated using Penman-Monteith method. Trend analysis of monthly and annual rainfall, potential evapotranspiration and rainfall deficit are essential to manage irrigation system in agricultural systems. This is because changes in trend of these parameters may affect the water cycle and ecosystem. Annual and monthly values of these variables were analysed from 19802009. Results indicated increasing trends of $16.2 \mathrm{~mm} \mathrm{yr}^{-1}$ and $3.01 \mathrm{~mm} \mathrm{yr}^{-1}$ for both annual rainfall and potential evapotranspiration, respectively. Consequently, these trends resulted in annual rainfall deficit of $1.69 \mathrm{~mm}$ per year.
\end{abstract}

Keywords: Rainfall, potential evapotranspiration,rainfall deficit, Penman-Monteith

\section{INTRODUCTION}

Rainfall is an important source of water for agricultural production. Rainfall is characterized by its amount, intensity and distribution within a period of time. Rainfall is often expressed in millimeters per day ( $\mathrm{mm} /$ day). Informations on the characterization of monthly or annual rainfall pattern in most parts of the country are generally available. From the agricultural perspective, rainfall is an important component because all plants need water to survive. While a regular rainfall pattern is essential to healthy crop to optimize its production, too much or too little rainfall can be harmful. Limitations in water availability are frequently a restrictive factor in plant development. Water is essential for the maintenance of physiological and chemical processes within the plant, acting as an energy exchanger and carrier of nutrient food supply in solution (Schulze et al., 1997).

As a component of rainfall, evapotranspiration is also a major climate variable affecting agricultural production and it is an important criteria of water management. The rate of potential evapotranspiration $\left(E T_{0}\right)$ is the amount of water that might be potentially lost due to evaporation over a vegetation surface. Evapotranspiration is correlated to solar radiation, air temperature, humidity and wind speed. Estimates of potential evapotranspiration was performed using Penman-Monteith (FAO-56 method) (Allen et al., 1998).

Studies in rainfall, $E T_{0}$ and rainfall deficit $(R D)$ trends at different time interval and region are very important for agriculture water balance, irrigation scheduling and cropping system management (Gary et al., 2016). Great concern has arrived in the past few decades on analyses of rainfall, precipitation and rainfall deficit trend because of the attention given to climate change from scientific community (Antonia and Paolo, 2009). Many studies have been conducted to address spatial and temporal trends both globally and locally. For example, Mohtar et al., (2014) studied recent changes in extremes of monthly mean rainfall distribution in the state of Perlis and Johore of Peninsular Malaysia over the period of 1970 to 1972 and 2010 to 2012, and made comparison between northern and southern regions, respectively. Their results showed that northern regions received heavier rainfall in 2010 to 2012 as compared to during 1970 to 1972. In another study, Syafarina et al., (2015) analyzed and compared hourly trends of rainfall during northeast and southwest monsoons of peninsula Malaysia between the years of 1975 to 2010. Their results showed that in general, the hourly extreme rainfall events in peninsular Malaysia showed an increasing trends in short temporal rainfall during inter-monsoon season. The rainfall, $E T_{0}$ and $R D$ has high spatial variability and therefore it is essential to conduct in local temporal characteristics, patterns and trends. In this study, data from years 1980 to 2009 at the Alor Setar station were used to analyze rainfall, $E T_{0}$ and $R D$ trends.

Alor Setar is the state capital of Kedah and encompassed an area of $424 \mathrm{~km}^{2}$. Kedah is also known as rice bowl state of Malaysia because of the large paddy granary areas. As most of other parts of Malaysia, Alor Setar features a tropical monsoon climate under the Köppen climate classification. Alor Setar has a very long wet season especially during August to September. During these period the rainfall received were normally 5 to $10 \mathrm{~mm} /$ day higher than other months (Tukimat and Harun, 2011). Similar to several other regions with this particular climate, precipitations are commonly seen even during the short dry season. Temperatures are relatively consistent throughout the year, with average high and low temperatures around 
$32^{\circ} \mathrm{C}$ and $23^{\circ} \mathrm{C}$, respectively. Alor Setar recorded an average of $2300 \mathrm{~mm}$ of precipitation per year. The Alor Setar meterological station is located in the north-western part of Peninsular Malaysia with coordinates $6^{\circ} 7 \mathrm{~N} 100^{\circ} 22^{\prime} \mathrm{E}$ as in Figure 1. This station is located in the major agricultural areas and hence, it is critical to understand temporal trends, pattern and variability of rainfall, $E T_{0}$ as well as $R D$.

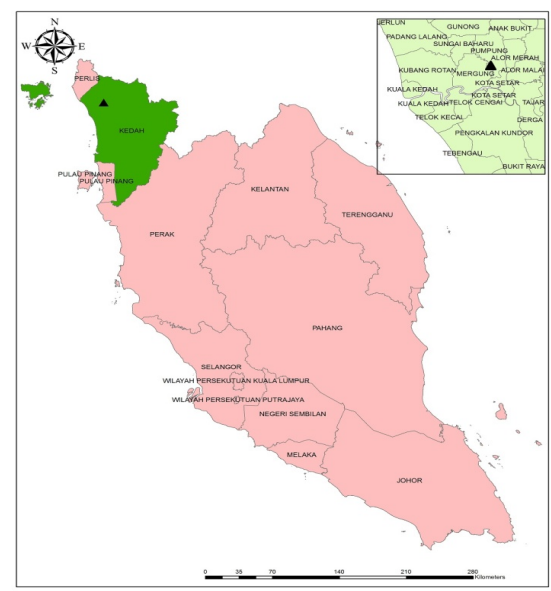

Figure 1 The location of Alor Setar station in Kedah, Malaysia.

The Mann - Kendall method has been widely used and tested to evaluate the presence of statistically significant trend in both climatological and hydrological studies. It is a nonparametric method and does not require any hypotheses of normal distribution and it is proven that any outliers of the data do not affect the results. For instance, Ijaz Ahmad, et al., (2015), successfully used Mann-Kendall test to detect trend in precipitation.Hence, the purpose of our study is to analyze the annual and monthly trend of rainfall, $E T_{0}$ and $R D$ in Alor Setar using Mann-Kendall method. Hopefully, the findings and information from this study can be useful for water management practices and cropping system in the area.

\section{METHODOLOGY}

\section{Historical weather data}

Historical data from 1980 to 2009 at weather stations in Alor Setar with latitude of 6.2 , longitude of 100.4 , and elevation $3.9 \mathrm{~m}$ above mean sea level were selected for the analysis. Rainfall data were obtained from Malaysian Meteorological Department while estimates of potential evapotranspiration were calculated using Penman-Monteith method.

\section{$E T_{0}$ calculation}

The estimated values of potential evapotranspiration are computed using Penman-Monteith (FAO-56 method) (Allen et.al, 1998) which is given as follow:

$E T_{0}$

$=\frac{0.408 \Delta\left(R_{n}-G\right)+\gamma \frac{900}{T_{\text {mean }}+273} \mu_{2}\left(e_{s}-e_{a}\right)}{\Delta+\gamma\left(1+0.34 \mu_{2}\right)}$

where

$E T_{0}$ - Potential evapotranspiration $\left(\mathrm{mmday}^{-1}\right)$ $\Delta$ - slope of the saturation vapor pressure function $\left(\mathrm{kPa}{ }^{0} \mathrm{C}^{-1}\right)$

$G$ - soil heat flux density $\left(\mathrm{MJ} \mathrm{m}^{-2} \mathrm{day}^{-1}\right)$

$\gamma$ - Psychometric constant $\left(\mathrm{kPa}^{0} \mathrm{C}^{-1}\right)$

$T$ - mean air temperature $\left({ }^{\circ} \mathrm{C}\right)$

$u_{2}$ - average $24 \mathrm{~h}$ wind speed at $2 \mathrm{~m}$ height $\left(\mathrm{ms}^{-1}\right)$

$R_{n}$ - net radiation at the crop surface $\left(\mathrm{MJ} \mathrm{m}^{-2}\right.$ day $\left.^{-1}\right)$

$-e_{s}-e_{a}$ saturation vapour pressure deficit $(\mathrm{kPa})$
A good estimation of potential evapotranspiration is important for proper water management, allowing for improve efficiency of water use and cropping management. There are several methods that have been developed to estimate $E T_{0}$. Some of the methods need many weather parameters while others need fewer inputs. For example, Thornthwaite (1948) used average daily temperature in calculating $E T_{0}$ because of the strong correlation between radiation and mean air temperature. Data availability is one of the factor in deciding what method to choose in calculating the estimates of $E T_{0}$. The PenmanMonteith method was used in this study because it is simple and representative of the physical and physiological factor governing the evapotranspiration process (FAO, 1998). This approach considered an imaginative crop with fixed parameters and resistance coefficients. Comparative studies carried out by (Smith et.al, 1992) and (Ali and Shui, 2008) found that Penman-Monteith was the best method because of its universal applicability.

\section{Rainfall deficit}

Rainfall deficit $(R D)$ was calculated using the difference between rainfall and potential evapotranspiration data. When the difference is negative, rainfall is less than evapotranspiration and it is called rainfall deficit. On the other hand, when rainfall exceeds evapotranspiration, this can be referred to as rainfall surplus $(R S)$ (Gary et.al, 2016)

$$
\begin{aligned}
R D & =\text { Rainfall }-E T_{0} ; \text { rainfall }<E T_{0} \\
R S & =\text { Rainfall }-E T ; \text { rainfall }>E T_{0}
\end{aligned}
$$

\section{Mann-Kendall method}

Mann-Kendall trend test is an applicable technique for identifying and interpreting the trend pattern of rainfall, $E T^{0}$ and $R D$ time series data. The Mann-Kendall trend test is evaluated based on the correlation between the observed ranks and order of time. The application trend is expressed as

$$
\begin{aligned}
& S=\sum_{i=1}^{n-1} \sum_{j=i+1}^{n} \operatorname{sign}\left(x_{j}-x_{i}\right) \\
& \operatorname{sign}\left(x_{j-} x_{i)}=\left\{\begin{array}{c}
1 ; x_{i}<x_{j} \\
0 ; x_{i}=x_{j} \\
-1 ; x_{i}>x_{j}
\end{array}\right.\right. \\
& V(S)=\frac{n(n-1)(2 n+5)}{18} \\
& Z= \begin{cases}\frac{(S-1)}{\sqrt{V(S)}} & ; S>0 \\
0 & ; S=0 \\
\frac{(S+1)}{\sqrt{V(S)}} & ; S<0\end{cases}
\end{aligned}
$$

where $\left\{x_{t}: t=1,2, \ldots, n\right\}$ is a time series for $n$ sample size.

Positive values of $Z$ indicate increasing trends while negative values indicate decreasing trends. Test hypothesis for this MannKendall test is described as follows:

$$
\begin{gathered}
H_{0}: \text { there is no trend } \\
H_{a}: \text { there exist a monotonic trend }
\end{gathered}
$$

At the significance level $\alpha=0.1$ if $|Z|>Z_{1-\left(\frac{a}{2}\right)}$, then $H_{0}$ is rejected and a significant trend exist in the time series.

The direction and magnitude of the trend in time series data were determine by using Sen's slope (Sen, 1968). Sen's slopeb, is calculated by 


$$
b_{i}=\frac{x_{j}-x_{i}}{j-i}, i=1,2, \ldots, N, \quad j<i
$$

The Sen's estimator of the slope is the median of these $N$ values of $b_{i}$. The sign of $b$ reflects the direction of trend data while the value represents the magnitude of the data.

\section{RESULTS AND DISCUSSION}

A preliminary analysis was conducted using basic descriptive statistics to give an early understanding of the data. These include data on mean, standard deviation, median, minimum and maximum values of the parameters. Further to this, coefficient of variation, skewness and kurtosis were also determined for rainfall, potential evapotranspiration and rainfall deficit during the time period.

\section{Rainfall}

Table 1 showed descriptive statistics of annual and monthly rainfall time series for Alor Setar station from 1980 to 2009. The mean annual rainfall is $2017.92 \mathrm{~mm}$ and annual rainfall varies from $2573.6 \mathrm{~mm}$ to $1429.5 \mathrm{~mm}$. October is the wettest month with highest mean rainfall of $287.25 \mathrm{~mm}$ while the driest month is January with lowest mean rainfall of $22.50 \mathrm{~mm}$. Annual rainfall and rainfall in month of October are negatively skewed. Coefficient of variation (CV) were calculated to determine the variability of the rainfall. The $\mathrm{CV}$ for annual rainfall is low indicating low variability but the coefficient for monthly rainfall were quite high (ranging from 0.43 to 1.7 ) for most of the months except for February, September and October. Large variations of $\mathrm{CV}$ indicate that rainfall is highly variable in these months.
Highest $\mathrm{CV}$ in January suggest greater challenges for water management in the area since it is the month of maximum paddy growth. During this month, efficient irrigation system is critical to maximize rice productivity.

\section{Potential Evapotranspiration, $E T_{0}$}

Table 2 showed descriptive statistics of $E T_{0}$ for annual and monthly time periods. The mean value for annual $E T_{0}$ was $1823.76 \mathrm{~mm}$ and it ranges between 1105 to $2054 \mathrm{~mm}$. Unlike rainfall, $E T_{0}$ does not indicate much variation over the years. As expected, the first quarter of the year shows higher mean value of $E T_{0}$ compare to low amount of rainfall in January, February, March and April. Mean monthly of $E T_{0}$ range from 165 to $192 \mathrm{~mm}$ and rainfall ranges between 22.5 to $206 \mathrm{~mm}$ in those months.

\section{Rainfall Deficit, RD}

Rainfall deficit, $R D$ is the difference between rainfall and $E T_{0}$ and annual mean of $R D$ was $194.17 \mathrm{~mm}$ (Table 3). Positive values indicate that there were rainfall surplus rather than deficit in Alor Setar station during the 29 year period. However, there were 8 years with rain deficit; 1987,1989, 1990, 1992, 1993,1994,1995,1998 and 2001. Amongst these, the year 1992 had the highest rain deficit $(535 \mathrm{~mm})$ indicating severe drought conditions. For monthly time scale, the months of January, February March and December experienced rain deficit with the mean value of $-154 \mathrm{~mm},-125 \mathrm{~mm},-45.65 \mathrm{~mm}$ and $55.54 \mathrm{~mm}$, respectively. It was proven that with less amount of rainfall, highest $\mathrm{ET}_{0}$ were recorded in these months suggesting they were the yearly drought months.

Table 1 Descriptive statistics of annual and monthly rainfall data in Alor Setar.

\begin{tabular}{lcccccccc}
\hline & Mean & $\begin{array}{c}\text { Standard } \\
\text { deviation }\end{array}$ & Median & Min & Max & Skewness & Kurtosis & CV \\
\hline Annual & 2017.92 & 288.66 & 2054.2 & 1429.5 & 2573.6 & -0.15 & -0.67 & 0.14 \\
Jan & 22.50 & 38.32 & 4.30 & 0.0 & 179.9 & 0.95 & 0.15 & 1.70 \\
Feb & 56.83 & 56.82 & 34.20 & 0.0 & 215.6 & 0.96 & 0.94 & 0.10 \\
Mar & 146.72 & 82.79 & 126.15 & 30.9 & 405.0 & 0.60 & -0.39 & 0.56 \\
Apr & 206.86 & 112.04 & 188.00 & 38.3 & 462.0 & 0.34 & -0.97 & 0.54 \\
May & 197.54 & 93.75 & 182.35 & 53.8 & 381.1 & 1.08 & 0.94 & 0.47 \\
Jun & 144.85 & 70.97 & 129.40 & 53.3 & 359.8 & 0.69 & -0.44 & 0.49 \\
Jul & 196.80 & 85.54 & 175.30 & 85.2 & 416.1 & 0.43 & 0.50 & 0.43 \\
Aug & 210.86 & 89.99 & 214.00 & 42.8 & 468.4 & 0.46 & -1.22 & 0.43 \\
Sep & 251.22 & 87.39 & 233.85 & 145.5 & 413.8 & 0.21 & -0.95 & 0.35 \\
Oct & 287.25 & 83.95 & 293.20 & 149.8 & 453.6 & -0.12 & -0.87 & 0.29 \\
Nov & 205.37 & 91.99 & 215.90 & 28.9 & 371.8 & 0.81 & -0.42 & 0.45 \\
Dec & 91.14 & 62.91 & 67.40 & 18.1 & 249.6 & 2.56 & 7.11 & 0.69 \\
\hline
\end{tabular}


Ahmad et al. / Malaysian Journal of Fundamental and Applied Sciences Special Issue on Some Advances in Industrial and Applied Mathematics (2017) 400-404

Table 2 Descriptive statistics of annual and monthly $E T_{0}$ data in Alor Setar.

\begin{tabular}{|c|c|c|c|c|c|c|c|c|}
\hline & Mean & $\begin{array}{l}\text { Standard } \\
\text { deviation }\end{array}$ & Median & Min & Max & Skewness & Kurtosis & CV \\
\hline Annual & 1823.76 & 323.28 & 1955.98 & 1105.93 & 2054.81 & -1.6 & 0.75 & 0.18 \\
\hline Jan & 176.72 & 37.23 & 188.95 & 94.20 & 211.89 & -1.29 & 0.20 & 0.21 \\
\hline Feb & 181.83 & 41.95 & 192.22 & 84.59 & 228.40 & -1.26 & 0.27 & 0.23 \\
\hline Mar & 192.38 & 42.07 & 199.20 & 102.25 & 244.39 & -1.06 & 0.02 & 0.22 \\
\hline Apr & 165.38 & 35.26 & 172.51 & 87.95 & 214.92 & -0.99 & -0.10 & 0.21 \\
\hline May & 142.96 & 24.50 & 149.21 & 91.91 & 179.45 & -1.12 & 0.15 & 0.17 \\
\hline Jun & 132.10 & 20.35 & 139.51 & 86.86 & 150.05 & -1.55 & 0.67 & 0.15 \\
\hline Jul & 137.23 & 22.09 & 145.84 & 86.32 & 157.46 & -1.54 & 0.66 & 0.16 \\
\hline Aug & 141.32 & 23.93 & 148.83 & 85.63 & 168.84 & -1.44 & 0.56 & 0.17 \\
\hline Sep & 134.21 & 21.61 & 140.69 & 83.45 & 156.93 & -1.40 & 0.50 & 0.16 \\
\hline Oct & 137.16 & 22.12 & 143.39 & 90.94 & 163.23 & -1.08 & -0.11 & 0.16 \\
\hline Nov & 135.80 & 23.35 & 141.65 & 86.90 & 170.42 & -0.94 & -0.23 & 0.17 \\
\hline Dec & 146.68 & 29.83 & 157.37 & 82.63 & 182.55 & -1.07 & -0.13 & 0.20 \\
\hline
\end{tabular}

Table 3 Descriptive statistics of annual and monthly $R D$ data in Alor Setar.

\begin{tabular}{|c|c|c|c|c|c|c|c|c|}
\hline & Mean & $\begin{array}{l}\text { Standard } \\
\text { deviation }\end{array}$ & Median & Min & Max & Skewness & Kurtosis & CV \\
\hline Annual & 194.17 & 430.27 & 116.82 & -535.89 & 1363.57 & 0.96 & 0.73 & 2.22 \\
\hline Jan & -154.23 & 54.93 & -178.22 & -211.89 & 17.52 & 1.30 & 1.13 & -0.36 \\
\hline Feb & -125.00 & 71.47 & -119.79 & -228.40 & 46.88 & 0.32 & -0.78 & -0.57 \\
\hline Mar & -45.65 & 97.29 & -43.15 & -212.14 & 220.15 & 0.36 & -0.13 & -2.13 \\
\hline Apr & 41.48 & 127.39 & 32.39 & -160.72 & 374.05 & 0.74 & 0.20 & 3.07 \\
\hline May & 54.58 & 103.51 & 34.95 & -100.78 & 288.42 & 0.57 & -0.44 & 1.90 \\
\hline Jun & 12.75 & 72.16 & 2.55 & -81.61 & 222.21 & 0.88 & 0.35 & 5.66 \\
\hline Jul & 57.13 & 94.83 & 47.19 & -72.26 & 278.49 & 0.53 & -0.75 & 1.66 \\
\hline Aug & 69.54 & 88.00 & 70.88 & -109.84 & 312.37 & 0.39 & 0.20 & 1.27 \\
\hline Sep & 117.01 & 93.69 & 101.38 & 1.70 & 324.21 & 0.45 & -1.11 & 0.80 \\
\hline Oct & 150.09 & 82.87 & 146.33 & -11.05 & 329.89 & 0.13 & -0.74 & 0.55 \\
\hline Nov & 69.57 & 97.96 & 68.89 & -132.82 & 240.24 & -0.19 & -0.95 & 1.41 \\
\hline Dec & -55.54 & 77.62 & -74.54 & -152.94 & 83.70 & 0.41 & -1.32 & -1.40 \\
\hline
\end{tabular}

Table 4 Mann-Kendall test result, $Z$ and Sen's slope, $b$ of annual and monthly rainfall, $E T_{0}$ and $R D$ trend in Alor Setar Station.

\begin{tabular}{|c|c|c|c|c|c|c|c|c|c|c|c|c|c|c|}
\hline & & Annual & Jan & Feb & Mar & Apr & May & Jun & July & Aug & Sep & Oct & Nov & Dec \\
\hline \multirow[t]{2}{*}{ Rainfall } & $Z$ & $1.9^{*}$ & 1.4 & 0.9 & 1.8 & 1 & $-2^{* *}$ & 1.7 & 0.4 & 1 & -1.5 & 0.2 & 0.2 & 0.9 \\
\hline & $b$ & 16.2 & 0.23 & 0.74 & 3.68 & 3 & -4.56 & 2.18 & 0.61 & 2 & -2.8 & 0.6 & 0.67 & 1.17 \\
\hline \multirow[t]{2}{*}{$E T_{0}$} & $Z$ & 1 & 0.9 & 1.5 & 1.4 & 1.4 & 1.5 & $2.5^{\star *}$ & $2^{* *}$ & $3.1^{* \star}$ & $3.6^{\star *}$ & $2.6^{\star *}$ & $2.7^{* \star}$ & 1.1 \\
\hline & $b$ & 3.01 & 0.63 & 0.93 & 1.39 & $\begin{array}{c}1.0 \\
5\end{array}$ & 0.64 & 0.51 & 0.45 & 0.88 & 1.02 & 1.06 & 1.27 & 0.63 \\
\hline \multirow[t]{2}{*}{$\begin{array}{l}\text { Rainfall } \\
\text { deficit }\end{array}$} & $Z$ & 0.1 & -1 & -0.8 & 0.4 & 0.5 & $-2.4^{\star *}$ & 0.6 & -0.2 & 0.4 & $-2.3^{\star *}$ & -0.6 & -0.3 & 0.2 \\
\hline & $b$ & 1.69 & -0.99 & -1.13 & 0.84 & 1.6 & -5.72 & 1.1 & -0.51 & 0.41 & -4.22 & -1.09 & -1.34 & 0.41 \\
\hline
\end{tabular}

\section{Trend Analysis}

The Mann-Kendall test was performed to see whether there is a significance trend on rainfall, $E T_{0}$ and $R D$ time series data. The magnitude of trends was determined using Sen's slope, $b$. The test show significantly increasing trend of annual rainfall $\alpha=0.1$ with the magnitude of $16.2 \mathrm{~mm}$. In contrast, there is no statistically significant trend for $E T_{0}$ and $R D$.
Statistically decreasing trend was detected for rainfall and $R D$ time series during the months of May and September during the 29 year period. These suggest that rainfall deficit has greater influence on the rainfall trend rather than $E T_{0}$ rate. A significant upward trend of $E T_{0}$ was observed in the months of Jun, July, August, September, October and November (5\% significance level) indicating rainfall deficits in these months due to high evapotranspiration rate. 


\section{CONCLUSION}

A successful water management planning system can be achieved by understanding the statistical properties of historical data of major climatic factors such as rainfall and evapotranspiration. This study analyzes trends in annual and monthly scales of rainfall, potential evapotranspiration and rainfall deficit parameters at Meteorological station in Alor Setar. The time duration involve in this study was 29 years (1980 to 2009). There were significantly increasing trends in rainfall, $E T_{0}$ and $R D$ over the 29 years. However, only annual rainfall show a statistically significance upward trend with the magnitude of

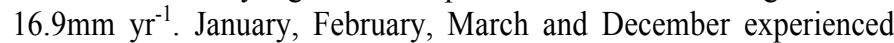
hot condition where rainfall amount is less than evapotranspiration rate which contribute to deficit in rainfall.

The major finding of this study is to present a successful method to investigate annual and monthly trends in rainfall, $E T_{0}$ and $R D$ using past years of meteorological data. These information are particularly important in Alor Setar area as to improve the water management system of rice cultivation in the MADA area. The use of $R D$ for example is helpful in determining the period of water deficit that affect the crop water requirements and the need for irrigation. This study could also give reliable information to improve water management decision in this particular area for greater water-use efficiency. Consequently, this method could also be applied in other areas to achieve similar objectives.

\section{ACKNOWLEDGEMENT}

This work was financially supported by the Ministry of High Education (MOHE), STEM Grant with vote no. A. J091002.5600.07397.

\section{REFERENCES}

Allen, R. G., Pereira, L. S., Raes, D. and Smith, M. 1998. Crop evapotranspiration: Guidelines for computing crop water requirements. Irrigation and Drainage Paper No. 56. Food and Agriculture Organization of the United Nations, Rome, Italy. Retrieved from http://www.hidmet.gov.rs/podaci/agro/table\%20of\%20contens_files.pdf

Ali, M. H. and Shui, L. T. 2009. Potential evapotranspiration model for Muda irrigation project, Malaysia. Water Resource Management. 23, 57-69.

Antonia, L., Paolo, V. Trend analysis and seasonal rainfall time series in the Mediterranean area. 2009. International Journal of Climatology. 30(10), 1538-1546.

Gary, F., Stacy, C., Zaid, A., Daniel, K. F., Ying, O., Ardeshir, A. and Johnie, N. J. 2016. Trend analysis and forecast of precipitation, reference evapotranspiration and rainfall deficit in Blackland Prairie of Eastern Mississippi. Journal of Applied Meteorology and Climatology. 55, 14251439.

Ijaz, A., Deshan, T., Tian, F. W., Mei, W. and Bakhtawar, W. 2015. Precipitation trends over time using Mann-Kendall and Spearman's rho tests in Swat River basin, Pakistan. Advance in Meteorology. 2015, 1-15.

Mohtar, Z. A., Yahaya, A. S., Ahmad, F., Suri, S., and Halim, M. H. 2014 Trends for daily rainfall in Northern and Southern region of Peninsular Malaysia. Journal of Civil Engineering Research. 4(3A), 222-227.

Smith, M., Allen, R. G., Monteith, J. L., Pereira, L. S. Perrier, A. and Pruitt, W. O. 1992. Report on the expert consultation on procedures for revision of FAO guidelines for prediction of crop water requirements. Land and Water Development Division, United Nations. Food and Agriculture Service, Rome, Italy.

Schulze,W., Dayan, P. and Read,. M. P. 1997. A neural substrate of prediction and reward. Science. 275(5306), 1593-1599.

Sen, P. K. Estimates of the regression coefficient based on Kendall's tau. 1968. Journal of American Statistics Association. 63, 1379-1389.

Syafarina, A. H., Zalina, M. D. and Juneng, L. 2015. Historical trend of hourly extreme rainfall in Peninsular Malaysia. Theoretical and Applied Climatology. 1201(1-2), 259-285.

Thornthwaite, C. W. An approach toward a rational classification of climate.1948. Geographical Review. 38, 55-95.

Tukimat, N. N. A. and Harun, S. The projection of future rainfall change over Kedah, Malaysia with the statistical downscaling Model. Malaysian Journal of Civil Engineering. 2011. 23(2), 67-79. 